\title{
Subversive Humor as Art and the Art of Subversive Humor
}

\begin{abstract}
This article investigates the relationships between forms of humor that conjure up possible worlds and real-world social critiques. The first part of the article will argue that subversive humor, which is from or on behalf of historically and continually marginalized communities, constitutes a kind of aesthetic experience that can elicit enjoyment even in adversarial audiences. The second part will be a connecting piece, arguing that subversive humor can be constructed as brief narrative thought experiments that employ the use of fictionalized scenarios to facilitate an open, playful attitude, encouraging a space for collaborative interpretation. This interaction between humorist and audience is an aesthetic experience that is enjoyable in and of itself, as the feelings of mirth are intrinsically valuable. But connected to the "Ha-ha!" experience of these sorts of humorous creations is an "Aha!" or potentially revelatory experience that is a mixture of cognitive comprehension and motivated (emotional) response. The third part of the article will attempt to go beyond the consciousness-raising element with an account of how such possible worlds created in the realm of imagination through subversive humor can bleed into the real world of flesh and blood people. Finally, an example of subversive humor will be analysed.
\end{abstract}

Keywords: Aesthetics; Humor; Imagination; Oppression; Thought Experiment; Racism

\section{Introduction}

The following example from comedian Aamer Rahman will illustrate an appeal to imagination in a creative, critical, thought-experimental, aesthetic experience that also appeals to our reason but without the use of straightforward argument. I will return to this example of subversive humor throughout the article with a deeper analysis at the end:

A lot of White people say this to me: "Hey Aamer, hey. You get on stage, you make your jokes about White people, you say "White people this, White people that." What if I did something like that, huh? What if I got on stage and said yeah, "Black people are like

* Santa Barbara City College; cakramer1@pipeline.sbcc.edu 
this, Muslims are like that.” You'd probably call me a racist, wouldn't you? “And I say, "Yeah, yeah I would"... They're like, "Well you do that Aamer!... you make your jokes about White people. Don't you think that's a kind of a racism? Don't you think that's... dun dun duuun... reverse racism?" I said, "No, I don't think that's reverse racism”... I think there is such a thing as reverse racism, and I can be a reverse racist, if I wanted to. All I would need would be a time machine, right? And what I'd do is I would get in my time machine and I'd go back in time to before Europe colonized the world, right? And I'd convince the leaders of Africa, Asia, the Middle East, Central and South America to invade and colonize Europe, right? Just occupy them, steal their land and resources. Set up some kind of like, I don't know, Trans-Asian slave trade, where we exported white people to work on giant rice plantations in China. Just ruin Europe over the course of a couple centuries, so all their descendants would wanna migrate out and live in the places where black and brown people come from. Of course in that time, I'd make sure I set up systems that privilege black and brown people at every conceivable social, political and economic opportunity. And white people will never have any hope of real self-determination. Every couple of decades make up some fake war as an excuse to go bomb them back to the Stone Age and say it's for their own good because their culture's inferior. And just for kicks, subject white people to colored people's standards of beauty, so they end up hating the color of their own skin, eyes and hair. If, after hundreds and hundreds and hundreds of years of that, I got on stage at a comedy show and said, "Hey, what's the deal with White people? Why can't they dance?” That would be reverse racism (Rahman 2013). ${ }^{1}$

\section{Subversive Humor as Aesthetic Experience}

For the purposes of this article, I stipulate that "subversive humor" is a form of protest or resistance to systemic structures of oppression or an unjust status quo. It is at once serious in the sense that its content is impactful and significant and that its motivations are critical, yet it is also playful in that it is open, creative, imaginative, and capable of cultivating such qualities in audiences-the laughter invoked is contagious, but so too are the attitudes and ideas. In this way, the view of humor I espouse is distinct from a relief or release theory which claims, in general, that humorous laughter offers a means of discharging physical or psy-

1 Special thanks to Jenn Marra for directing me to this example. I focus on a stand-up performance because it is readily accessible by a wide audience, situated within an understandable context, and far easier to analyze than anecdotal, spontaneous instances of humor. However, it would be informative to study in depth the methods and successes of subversive humorists who engage in "guerrilla" tactics. For some discussions of the subversive feminist group, The Guerilla Girls, see Morreall 2009, 70, and of Krokidil in Soviet Russia, see Morreall 1983, 102. 
chological tension and pent-up energy. Humor can do this, but it is not the sole function of subversive humor. ${ }^{2}$

It is not obvious that humor qualifies as art, especially if one includes jokes, anecdotes, amusing riddles, role-reversals, and everyday conversational wittiness. It is even less intuitive to include subversive humor under the aesthetic umbrella-what is pleasurable, appealing, to say nothing of sublime, about political and social protest against oppression? More to the point here, what are the benefits of placing subversive humor within the boundaries of aesthetics for humor scholarship and/or for those actually suffering under oppression, on behalf of whom subversive humorists create? The first part of this article explores these questions.

My thesis assumes that the arts in general are aesthetically, epistemically, and ethically valuable, following the work of Nelson Goodman: "the arts must be taken no less seriously than the sciences as modes of discovery, creation, and enlargement of knowledge...” (Goodman 1978, 102). The successful instances of aesthetic constructions facilitate the free play of ideas, unfettered by rules imposed externally on the experiencer, but also those artworks that foster an appropriate emotional distance from the work that can induce one to pleasurable reverie. But the sort of aesthetic experiences I am interested in are not "pure" in Immanuel Kant's sense, which offer pleasure solely in the perception of the aesthetic object. Pure aesthetic experience is sustained for its own sake as we are not engaged in the experience for any other reason than the enjoyment it brings. Aesthetic experiences created for the purpose of raising consciousness about an unjust reality e.g., cannot merely entice the pleasure centers of our brains; they must also challenge us to see and think differently, and thus they are not designed only to offer an outlet for audiences to "blow off steam." The fictionalized settings of some artworks enable us to enjoy our experience even when it might be directing our attention to something morally unpleasant, but as I will argue below, an aesthetic experience properly generated can place audiences in an emotional and cognitive sweet spot-they are not too close to the content that it cannot be enjoyed (or critically analyzed), nor are they too distant from it that it has no interest to them, and thus offer no motivation to spend any time with it.

There are many examples of subversive art that appeal to our emotions but also foster critical reflection as they motivate by way of imagination, creating

2 For more on the Relief theory see Freud 1960; Morreall 1983, 20 -37; Roberts 2019, 91-93. Works of art can be cathartic in the sense that they provide a release, but if this is all that they do, one may question the efficacy of such a mode of resistance. 
novel ways of perceiving and thinking about some element of our world. On one account, any work of art is subversive by its very nature. Reminiscent of Albert Camus’s essay “Create Dangerously,” though without referencing Camus, Stanley Diamond in his "Subversive Art" opens with the categorical claim that "All art, worthy of the name, is subversive, subversive of civil society, of civilization" (Diamond 1982, 854). ${ }^{3}$ This is too strong, and in fact, unwittingly lends undue credence to artworks that are designed expressly for the purposes of maintaining an unjust status quo rather than questioning it: see Leni Riefenstahl's Triumph of the Will or John Tenniel's Irish Devil-Fish for just two examples. ${ }^{4}$ These are creations coming from the top, so to speak, punching down at those without power in order to keep it that way. Not coincidentally, this punching imagery is integral in humor, especially the subversive sorts which intend to hit their audiences with their conclusion/punchline from below.

There is no question that jokes and laughter can be used as a tool of oppression, as a means to maintain pernicious stereotypes from the consciously and explicitly racists at WAR (white Aryan resistance) to the putatively well-meaning millennials who use racist and racialized jokes when out of earshot of minorities that further perpetuate white supremacy. ${ }^{5}$ While there is not space to fully address this matter, it is helpful to note some features common to subversive art/humor that are not found in oppressive rhetoric, even if artistic. Jose Medina provides a contrast between the epistemic virtues of oppressed people and the vices of the privileged that might be useful here. Consider the "three epistemic virtues: humility, curiosity/diligence, and open mindedness. As they appear among the oppressed, these epistemic virtues are the mirror-images of the epistemic vices of the privileged (arrogance, laziness, and closed-mindedness)" (Medina 2013, 43). Such a contrast is informative in analyses of subversive artworks in general.

3 Diamond qualifies this categorical claim by pointing out that in some cases, totalitarian regimes, e.g., the artist can become a "lapdog" producing the "official art" of the regime constituting the "boring translation of a repressive bureaucratic structure" (Diamond 1982, 855). But he does not tell us whether this fact renders the work non-artistic or non-subversive and why. 4 It is true one might retort that what was being "subverted" in that case was the Nazi-fabricated menace of Judaism. But as I will argue below, subversion implies a confrontation "from below" or from the "outside" or "borders" or "margins" of society. There is not space to investigate this matter here, but we can still possibly enjoy some aspects of Riefenstahl's film, a particularly unique camera angle, as we might derive aesthetic pleasure from the use of shading or line in Tenniel's drawings without being committed to the cognitive content in either one of the works.

5 For an overview of recent research into how millennials view race and racism today (they are not less racist than their parents, just differently so), see DiAngelo 2018, 47-50. 
The use of stereotypes in the jokes created and performed by oppressors is motivated by the goal of system justification; this is not the case with the subversive humorist. The oppressive person wishes the stereotypes were true; the subversive attempts to reveal that they are not. The subversive humorist fosters in themselves and imbues in others a playful acceptance of ambiguity, dynamism, incongruity, and "ontological confusion" (Lugones 2003, 86). ${ }^{6}$ The "humor" from above in the "winners' circle (Harvey 2010, 7) consists of ridiculing barbs spewed from a place of aggressive and arrogant ignorance: "In the same way that the three vices of privileged subjects converged in what I called active ignorance, the three virtues of oppressed subjects also have a converging point: a special kind of lucidity, subversive lucidity, which can take different forms, including critical and experiential lucidity” (Medina 2013, 45; my italics). It is not surprising that those on the margins of society tend to have an epistemic advantage in recognizing oppression. ${ }^{7}$

Rather than delve into the morass of defining "art” I will simply offer a brief

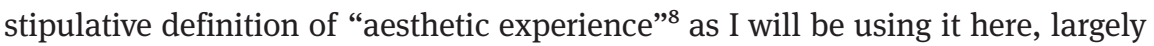
following John Morreall (Morreall 1983, 1987a, 1999, 2009), and then show how subversive humor fits within that conception, providing possible avenues toward "subversive lucidity." For Morreall, a humorous aesthetic experience is one where an "incongruity is enjoyed for its own sake, the enjoyment of a conceptual shift by itself”(Morreall 1983, 93; see also Gordon 2012, 63). He advances a version of the Incongruity Theory ${ }^{9}$ of humor:

6 Lugones also coins the wonderful phrase "curdled logic" which favors dynamism, permeable boundaries among "worlds," and the creation of tensions which lay the groundwork for "epistemic shift[ing]" among multiple views, thereby pacifying "aggressive ignorance" (Lugones 2003, 18) - this is in contrast to a logic of purity. Lugones's perspective on resisting oppression is influential here: "My perspective is in the midst of people mindful of the tensions, desires, closures, cracks, and openings that make up the social" (Lugones 2003, 5), and that it is a "playful attitude" that allows us to "Notic[e] the tensions from within a logic of resistance [that] enables one to acquire a multiple sensing, a multiple perceiving, a multiple sociality" (Lugones 2003, 11).

7 For a compelling case related to racism in the context of the "quotidian," see Yancy 2008, $843-76$.

8 Admittedly, "art" fits better for a clever title, but I will be using the broader term "aesthetic" for this article.

9 For an overview of this history see Morreall 1983, 1-59; Hurley et al. 2011, 37-56; Buckley $2005,3-48$, and for a defense of an incongruity theory against competing views such as Superiority and Relief/Release theories, see Oring 2003, 1-12; Marmysz 2003, 123-54. Other terms often used as synonyms to define/explain incongruity have been ludicrousness, ridiculousness, the unexpected, contradiction, paradox, absurdity, something inappropriate or inconsistent, a 
1. We experience a cognitive shift-a rapid change in our perceptions or thoughts.

2. We are in a play mode rather than a serious mode, disengaged from conceptual and practical concerns.

3. Instead of responding to the cognitive shift with shock, confusion, puzzlement, fear, anger, or other negative emotions, we enjoy it.

4. Our pleasure at the cognitive shift is expressed in laughter, which signals to others that they can relax and play too. (Morreall 2009, 50; italics in original)

I agree with each of these points but with some important caveats. His conception of "disengaged" in play mode, and related to that in (3), his implication that humor is not an emotion but a blocker of emotion, both lead to problematic conclusions. I will address these two issues in the remainder of this section, beginning with the importance of emotions.

\subsection{Emotions and Aesthetic Experiences}

Morreall asserts that humor is not an emotion because it is either stifled by negative emotions, or it stifles these negative emotions. More significantly, he claims humor entails a lack of genuine concern with tracking the truth or changing the world and our perspectives of it, which is a key element of emotion. Morreall's account, which is in line with the majority view in the history of philosophy, erroneously divides the intellect from the emotions. ${ }^{10}$ I think it is accurate to claim that humor can undercut and/or offer an appropriate distance from the negative emotions experienced by those who are depressed, sick, or buried in existential angst in the midst of a seemingly absurd cosmos. It is also the case that the feeling of humor can be blocked or dissipated due to negatively valenced emotions like fear or rage. But neither of these points entails that there can be no humorous aesthetic experience so long as one is genuinely concerned about some aspect of reality. Following Mordechai Gordon, "humor is aesthetic to the extent

lack of harmony, having parts that do not fit together, etc. Of course, not all of these concepts are interchangeable with each other.

10 Within the history of Western thought philosophers have (negatively) associated body, emotion, irrationality with women, and mind, reason, rationality with (white) men: "As a consequence of these divisions, emotion and intellect, since they are qualitatively different endowments, come to be thought of as in perpetual conflict, unable to mix or cooperate with one another" (Marmysz 2003, 144). See also Monahan 2011, 160; Rooney 2010, 224-28; Lugones 2003, 107-18. This view has had multiple deleterious effects. 
that it arouses the viewers' imagination, provides them with insights about human existence, and provokes them to think more critically and creatively" (Gordon 2012, 66). These positive aspects are unlikely without some motivating, emotional factors in addition to a reasoned intellectual response.

Morreall claims that emotions in general, but those particularly possessed by tragic figures, "lock heroes into self-concern and into their own perspectives, just as they do to us in real life. With emotional states, we tend to act in automatic, habitual, less intelligent ways; and the stronger the emotion the less intelligent our actions" (Morreall 1999, 25). ${ }^{11}$ But if neurologist Antonio Damasio is correct, among many other contemporary theorists who regard emotional intelligence as essential to intelligence simpliciter, ${ }^{12}$ then we should infer from Morreall only that some emotions or some high level of an emotion can counteract/balance other emotions. Consider some of the evolutionary benefits of mirth: humor appreciation is an "adaptive aesthetic emotion," as Weisfeld puts it, "humor, like other arts, evolved and is cultivated in order to provide valuable experience to the receiver" (Weisfeld 2006, 2; Martin and Ford 2018, 19, 32-33, make a similar case). Like any pleasurable experience, there is a motivation to continue it or seek it out again to receive that reward of mirth.

This pleasure reward is valuable because it provides us with a playful nonthreatening space in which we can practice for the "real" world of ambiguity, confusion, and doubt: "Humor gives temporary legitimation to thinking in impractical and illogical ways, releasing the 'adventurous ideas' that are fundamental to creativity" (Ziv 1983, 69; see also Basu 1999, 388). Creativity is something worth cultivating, and one of the most effective ways to continually sustain an interest in doing that which is in our interests is to offer rewards. This rewarding feeling of mirth, like that experienced in play generally, is desir-

11 This would be true if he had qualified the statement with "some negative emotions," rather than tacitly assuming all emotions gear one toward non-rational, non-critical behaviors. Furthermore, even anger, a negative emotion in Morreall's perspective, is really only a vice when it connotes rage, which is the normalized tendency when used to describe the "dangerous" black male, or the overly emotional woman (see Lugones 2003, 107-18 for a positive rendering of justifiable anger when expressed by women who are responding to oppression). So, it is not at all clear that emotions as such are irrational or completely cut off from reason. An example could be borrowed from Antonio Damasio's Elliot's Problem, in which a patient is incapable of making real-world choices due to an absence of the relevant "emotional reactivity and feeling" Damasio 1994, 51; see also Gendler 2006, 190 -91. Elliot lacked emotional intelligence, something that cannot be separated from intelligence as such, contra Morreall.

12 See Elder 1996; Rooney 2010; and Minsky 1984 and Hurley et al. 2011, 73-92 on the need for emotionality in artificial intelligence. 
able in itself, but it is also instrumentally valuable as a mode of resistance beyond merely laughing off systemic oppression. ${ }^{13}$

Part of the pleasure comes from recognizing novel ways of representing reality, and one of the best means to bring this about is through tapping into imagination. I agree with Morreall here: "In the aesthetic frame of mind we are not locked into looking at things in just one way. We are free to shift our perspective, several times if we choose, see things as other things, and even build fictional worlds" (Morreall 1983, 90; my italics). Solving a puzzle or riddle, for example, provides us with pleasure and even delight as we arrive at a new way of seeing or thinking. When the feeling of mirth is experienced in subversive humor, the audience enters play mode, if it is not already in it, and is more open to challenges to their fundamental beliefs; they are in a position to enjoy and even seek out further, the temporary feelings (emotions) often invoked by humorists. These emotions are exploited even when we engage in what we know to be fictional material: "our cognitive architecture is such that without the tendency to feel something relevantly akin to real emotions in the case of merely imagined situations, we would be unable to engage in practical reasoning" (Gendler and Kovakovich 2006, 243; my italics). I will return to this point with thought experiments below.

The attitude that is evoked and perpetuated by humor fosters what Hurley et al. refer to as "open-ended thinking [and it] use[s] emotions like curiosity, boredom, doubt, confusion, insight, mirth, and the like." That is, these emotions motivate us to think (and rethink) about some complexity of reality and help us to make sense of it. ${ }^{14}$ This is an attitude inculcated by the arts generally which "call our attention to the complexities, ambiguities, and uncertainties of human existence... In short, aesthetic experiences can provide us a viewpoint on the human

13 See Martin and Ford 2018, 33 on recent research that shows how humor can foster positive emotions: "Unlike negative emotions, which tend to narrow an individual's focus of attention and actions... positive emotions broaden the scope of the individual's focus of attention, creating a wider range of behavioral response options. This in turn builds physical, intellectual, and social resources needed to cope with life's challenges and further contributes to the experience of positive emotions.”

14 Hurley et al. 2011, 81: "Motivation" and "emotion" are both derived from movere-to move: "Emotions as motivators provide a kind of rationality. They direct our behaviors, and they had better direct them in a reasonable manner, or evolution will punish them with extinction" (Hurley et al. 2011, 74). In starker terms they claim that "Humor is one part of the emotional mechanism that encourages the process that keeps data integrity in our knowledge representation. This process ensures that we reduce the likelihood of making faulty inferences and fatal mistakes. Without a trait like this, a cognitive agent as complex as we are would be practically guaranteed a quick death" (Hurley et al. 2011, 289). That's serious. 
condition that is both profound and liberating (Gordon 2012, 64). The feeling of confusion or doubt can be uncomfortable, even anxiety-inducing at times. But there is a strong tradition in philosophy starting at least with Socrates, the "non-violent gadfly," in which confusion or aporia can be viewed as a necessary stage in the progress toward truth, or at least the progression to the state of knowing that you cannot be as certain as you thought you were. Humor can facilitate a willingness to remain uncomfortable at least long enough to follow the thoughts of the wit and possibly reveal our cognitive incongruities. One of the reasons for this is that the experience of mirth is addicting as it affects similar reward centers of our brains as some drugs, and it is for this reason the phrase mirth addiction is an apt descriptor, ${ }^{15}$ but the side effects of humor are far less damaging, in fact, they are positive.

Without noticing that there are contradictions between our ideals and the actual way of the world, no amount of conscious, willful, egalitarian beliefs and desires will provide a resolution. The feelings of mirth in subversive humor play the role of priming the appropriate emotions helpful in motivating an audience to discover a hidden inconsistency and, if one genuinely holds the ideals to egalitarianism and truth-seeking, e.g., doing something about it. It offers an indirect unconventional means of raising consciousness about systemic conventional oppression and can succeed where traditional approaches have not.

\subsection{Playful Distance and Aesthetic Experiences}

Humor can elicit both a "funny huh" and "funny ha-ha"16 response where the audience is placed in a similar situation to those confronted by Socrates. When the humor involves purposeful ambiguity, or exaggeration and seeming absurdity, some kind of resolution, or better, some meaning salvaged from apparent ludicrousness, is needed in order for it to be enjoyed. This will require an appropriate distancing from the content of study in order for it to be comprehended and experienced as amusing, in much the same way philosophers must be sufficiently

15 For more on this evolutionary account comparing our addiction to mirth to that of sweets, sex, drugs, and music, see Hurley et al. 2011, 1, 26, 62, 81-82, 253, 290, 294; Weisfeld 2006, 3. For one general example, see Jones 2006, 131: "As the mesolimbic area contains dopamine-releasing 'reward centers,' these correlations provide support for the claim that finding funny is a physiologically pleasurable state."

16 See Morreall 1987a, 188-207 on the differences between "Funny Ha-Ha" and "Funny Strange," and Hurley et al. 2011, 27-34 on "Funny-ha-ha" and "Funny-huh." 
disinterested (not uninterested) in the subject under scrutiny in order to step back from it and view the matter from a wider perspective. This is especially the case when adopting a different view on a state of affairs entails seeing from a perspective that might be contrary to one's own.

The distance that is invoked by humorists comes about as they place the audience in a playful mode where surprise is relished and leads to enjoyment rather than anxiety. This "emotion of 'playfulness' is what encourages us to spend the energy on the games that constitute play" (Hurley et al. 2011, 80n20). But these "games" include serious tasks such as checking for flaws in our heuristic expectations whether they concern rules of language, society, or morality. These playful emotions allow for incongruity to stand out in ways it would not if we were too deeply ensconced in the details of one frame or too distant from that frame such that no meaningful connections could be made between/among patterns of thought.

In aesthetics, the concern might be framed in terms of seeking a "kind of a compromise between 'under-distancing' and 'over-distancing”' (Walton 1978, 22) in the construction of aesthetic fictional worlds, especially when the focus is on morality: "fictions belong to worlds which are different from ours... But why do we think of fictions as belonging to 'worlds' at all-as though they have a place (or places) somewhere in reality, however remote they may be from the actual world?" (Walton 1978, 19). An answer might lie in another work from Walton on imaginative resistance: "There is science fiction; why not morality fiction? [because]... we are less willing to allow that the works' fictional worlds deviate from the real world in moral respects than in nonmoral ones" (Walton and Tanner 1994, 35, 37). In other words, we are capable of thinking deeply and feeling deeply about the content in an aesthetic fiction because it matters to us, because it is connected to this world even when we are entrenched in that which is merely logically, not physically, possible-a common facet of philosophical thought experiment and quite a bit of humor as Rahman's inclusion of the time machine illustrates.

In both aesthetic experience and humor, one is interested in the enjoyment of the experience, and in this way, the artist and humorist alike cultivate what Morreall calls a "play mode" (Morreall 1983, 89). This playfulness provides the necessary logical and emotional space for the enjoyment and analysis of an aesthetic object. Like play, aesthetic experiences allow one to perceive the world from various perspectives, and derive pleasure from the creative, imaginative, and even liberating disengagement from the practical concerns in our immediate surroundings. But, like the artist, the humorist must comprehend the relevant elements of reality in its multitude of patterns, and continually be on the lookout for novel points of view. So, like play, humor is also instrumentally valuable: 
"The main ingredients of humor, surprise and incongruity, together with the idea that 'this is not for real,' should encourage some departure from the constraints of conventional thinking” (Ziv 1983, 70). Later Avner Ziv expounds on this line of thought: "Humor is a way of looking at things and phenomena 'as if'... Humor, like play, is an invitation to fantasy..." (Ziv 1983, 72). But this is not merely frivolous fancy. Put another way, there are real-world consequences to our imaginative aesthetic play.

The humorist, like the artist, attempts to reward her audience for connecting or juxtaposing putatively disparate ideas, images, or world-views. In the broadest sense of the term, we experience incongruity of some sort, and we like it as it offers us a view of the world that is not absolute, static, inexorable, or inflexible. In the next section I will investigate the role of aesthetic distance in humorous play with ideas: subversive humor that stokes our imaginations and our logical intuitions in thought experiments.

\section{Subversive Humor as Thought Experiment}

Philosophical thought experiments are conducted in the mind where pre-existing mental spaces are employed or new ones are constructed through the creative priming techniques of the experimenter. This is often accomplished by way of narrative analogy, especially in moral philosophy, as comparisons to unquestionably moral (or immoral) cases are made to highlight the wrongs (or justice) of a case in question. Sometimes these tactics call on elaborate philosophical tools that employ imagery, metaphor, and logically possible fantasy (Gendler 1998; Dennett 2013). Many cases of subversive humor are philosophical thought experiments that frame (or re-frame) an issue so as to reveal hidden assumptions, collaboratively invoke shared commitments, moral or otherwise, and attempt to change the biased attitudes of the audience. In this way, thought experiments and subversive, humorous play with words, concepts, and situations, are deeply connected. Some instances of subversive humor are a species of aesthetically pleasing thought experiments that are "devices of persuasion" (Gendler 2007, 80 - 86).

Tamar Gendler promotes a mental model account of thought experiment through which we can learn something new about the world even though there might not be any novel empirical data adduced with such experiments. In her words, we are reasoning about imaginary scenarios but with the goal of 
confirming or disconfirming a hypothesis. ${ }^{17}$ This understanding of thought experiment can be extended to help explain the potential persuasiveness of subversive humor. We can use thought experiments to gain a better conceptualization of some aspect of reality, usually by highlighting something that now seems obvious due to the clarity or compelling nature of the thought experiment, ${ }^{18}$ or by reframing an account of the world that was thought to be unquestionable, but is now justifiably held under a microscope, in some cases leaving us bewildered as to how we missed a given point or connection prior to the illuminative thought experiment.

Gendler notes that "Reasoning about particular entities within the context of an imaginary scenario can lead to rationally justified conclusions that-given the same initial information-would not be rationally justifiable on the basis of a straightforward argument... [the thought experiment is] a reconfiguration of internal conceptual space” (Gendler 1998, 397, 420). There is an important connection to imaginative aesthetic resistance to injustice here. Protest cannot rely solely upon spectacle (see Duncombe 2007, 31), but argument without imagination also leaves potential audiences wanting. There are arguments that can be made for the points being illustrated by the subversives, and we might even be able to reconstruct their performance into an argument, removing all of the indirect, non-bona-fide, ambiguous language, and imaginary scenarios. But we run the risk of losing something essential in such a logicist project, akin to attempting a literal and purely logical translation of a lexically economical poem. ${ }^{19}$ The thought experiment is worked through, as "experiment" connotes,

17 There is not space here to give an account of the current debate regarding the nature and efficacy of thought experiments, but see Gendler 1998, Taylor and Francis 1998, 392-97 for an overview.

18 Ernst Mach, who coins the phrase "thought experiment," asserts that our intuitions "are more easily and readily at our disposal than physical facts. We experiment with thought, so to say, at little expense" (Mach 1972, 452). We might rather say, at an expense that is worth the reward when it is coupled with humor.

19 There is a useful analogy between humor and poetry, namely between humor and metaphor, a central contrivance in a poet's arsenal. The wit is revealing something extra-ordinary about something most people deem ordinary, to borrow from Shelley on the role of poetry (see also Dennett 2013, 74). To answer concerns that this comparison is hyperbolic, consider that it is not coincidental that poetry (from poeisis-to create or make through playing with words outside of rules of conversation) and humor have some overlapping means to their ends, as both often trade in hidden meaning, economy of language, ambiguity, metaphor, irony, etc. The focus here is on two areas of overlap: (1) both poetry (primarily through the use of metaphor) and humor through creative juxtaposition and efficient use of words where much is left unsaid, intend/convey more than what is literally, explicitly, one-dimensionally stated and (2), both can reveal otherwise hidden assumptions that have enormous influence on how we think. Furthermore, both 
rather than reasoned through in the typical argumentative structure. This places humorous thought experiment in between two ends of a spectrum benefiting from both "worlds": pure aesthetic experience and pure logical argument. With humor we enjoy discovering the errors in our expectations, not direct valid inferences. Indeed, many instances of humor are structurally similar to logical fallacies, as I will illustrate below, but this does not make them any less persuasive-alas, perhaps, for logic professors, but significant for those seeking alternative means of consciousness-raising and protest.

Most openly egalitarian truth-seekers are quite capable of understanding the arguments put forth by theorists who have similar conclusions as Aamer Rahman in the opening bit, e.g., but, due to willful ignorance, an inclination to epistemic closure, and the desire to maintain the status quo at some level (many of the epistemic vices of the privileged discussed by Medina), direct strategies lose a degree of demonstrability and persuasiveness. Such arguments often fail to "tap into" the "stores of unarticulated knowledge of the world which is not organized under any theoretical framework" (Gendler 1998, 415). But a successful humorous thought experiment, like Rahmer's, "brings the [listener] to recognize the inadequacy of his conceptual framework for dealing with phenomena which -through the contemplation of this imaginary case-he comes to recognize as always having been part of his world" (Gendler 1998, 412). The historical facts ticked off by Rahmer, albeit facetiously in the form of counterfactuals, are already there in our web of beliefs, we just need a way to access them and organize them-confrontation by direct augmentation rarely has such effects. ${ }^{20}$

can reveal something of interest and importance about the mundane that most people in serious mode tend to ignore. Here is an example with humor: "Only in America do sick people have to walk to the back of the drugstore to get their prescriptions while healthy people can buy cigarettes at the front" (Hurley et al. 2011, 164). This example does not assume universal understanding; that is, the background relies upon specifically North American culture. While humor may be universal, there are very few if any universally humorous jokes. But humor has the effect of encouraging audiences to want to understand. Nobody wants to miss out on getting a joke. This is one difference between humor and poetry: at least in our current culture, one is more likely unperturbed when one fails to "get" a poem; this is not so with humor. I do not take playfulness as a necessary condition for poetry in the way I do for humor. Though there is not space in this article, there is a similar distinction to be made between humor and irony, where only the former requires the element of playfulness (see Rorty 1993, especially 12-13, 60 on poetry and metaphor; Sánchez 2012, 201 and Lear 2009, 281-83 on Socratic irony especially in the Euthyphro; and Geertsema 2004 on irony as a consciousness-raising tool against overt oppression in South Africa).

20 Current cognitive science, and Walter Lippmann, whose turns of phrase are more interesting, offer similar advice: "This is as true of the high politics of Isaiah as it is of the ward boss. Only the pathetic amateur deludes himself into thinking that, if he presents the major and minor 
The idea that some cases of humor are similar to or are a species of thought experiment can be found in the works of Arthur Koestler, David Gooding, and John Morreall, where the latter makes numerous comparisons between philosophy and humor. In brief, (1) ideally both are forms of conversation that rely upon interaction between/among interlocutors. (2) Both are often concerned with everyday banalities that the majority of the populace usually ignores, until they see the oddities for what they are by being confronted with a philosophical thought experiment or an amusing bit that might spread quickly online. (3) "In philosophizing about something or joking about it, we view it from a higher perspective than our normal one, [and here is where we do not completely agree]... they are practically detached from those experiences" (Morreall 2009, 127). (4) Both encourage that we look at the world and our place in it from novel perspectives. (5) Both humorists and philosophers are critical thinkers, open to analyzing common assumptions, including their own. Finally, "comedians and philosophers often think in counterfactuals, mentally manipulating possibilities as easily as most people think about realities" (Morreall 2009, 128). This last point is relevant to the aesthetic elements of humor.

More recently, Tony Veale argues that some jokes are truncated thought experiments in which "the role of imagination is vital, for jokes ask us to imagine scenarios that are so out of the ordinary that conventional modes or rules of behaviour appear to break down." Both jokes and thought experiments interrogate our presuppositions, Veale continues, such "that many jokes are, in fact, humorous thought experiments, in which the theories under revision are social norms, genre conventions and taboos" (Veale 2015, 69-70). His analysis borrows heavily from Gendler who claims that thought experiments are manifestations of exceptional cases, since these are best suited to expose flaws in our normal categorizations. I will also help myself to these ideas, connecting them with the research from Hurley et al.'s error-detection theory of humor. ${ }^{21}$

premises, the voter will automatically draw the conclusion on election day. The successful politician-good and bad-deals with the dynamics-with the will, the hopes, the needs and the visions of men." Quoted in Duncombe 2007, 36.

21 The connections between humor as error-detection device and thought experiment as an indirect persuasion device are compelling. Gendler asserts that "by presenting content in a suitably concrete or abstract way, thought experiments recruit representational schemas that were otherwise inactive, thereby evoking responses that may run counter to those evoked by alternative presentations of relevantly similar content... exactly because they recruit heretofore uninvolved processing mechanisms, thought experiments can be expected to produce responses to the target material that remain in disequilibrium with responses to the same material under alternative presentations, so that a true sense of cognitive equilibrium will, in many cases, prove elusive... when thought experiments succeed as devices of persuasion, it is because the evoked 
We are rewarded with the feeling of mirth for recognizing when a general rule of thumb or common bit of presumed scientific, political, social, or ethical wisdom we expect to hold actually fails, and we can now see that there is an exception to that heuristic. Surprisingly, there is an early instance of this idea in a joke from Arthur Schopenhauer: "The soldiers in the guard-room who allowed a prisoner who was brought in to join their game of cards, then quarreled with him for cheating, and turned him out." And here is Schopenhauer's analysis, which is necessary for us as his presentation of the joke is not superior: "They let themselves be led by the general conception, 'Bad companions are turned out,' and forget that he is also a prisoner, i.e., one who they ought to hold fast" (Schopenhauer 1887, 277-78). This is one of the examples of ludicrousness, according to Schopenhauer, in which a foolish action results from one erroneously subsuming realities under general conceptions.

It is a variety of the fallacy of Accident in which a general rule is followed and mitigating circumstances are ignored, as the theory, imperative, or general maxim takes precedence (when it should not) over concrete perception, or what Schopenhauer implies throughout, reality. So, mirth is "the motivation for a mind to search out subtle oversights made in reasoning that could infect the integrity of our knowledge" (Hurley et al. 2011, 12-13). Significantly, these errors are not explicitly pointed out to us by the subversive humorists. To do so would be to rob us of our "Aha!" and "Ha-ha" emotional and intellectual experiences, and thus, deprive us of the pleasures of mirth in the same way as finishing someone else's crossword puzzle or answering a riddle intended for another person would. The audience must collaborate in the meaning-making within the joke-world, which is a unique aspect of humorous thought experiments.

The subversive humorist is violating rules, but the audience will still be able to find and/or make meaning out of the wit's purposeful and playful employment of incongruity, absurdity, counterfactual, or hyperbolic analogy. Without at least this level of collaboration between humorist and audience, not only will they likely not comprehend the content, but they will also fail to enjoy

response becomes dominant, so that the subject comes (either reflectively or unreflectively) to represent relevant non-thought experimental content in light of the thought experimental conclusion” (Gendler 2007, 69). By "disequilibrium” Gendler means that one's reactions to the fictional story are not compatible to their reactions to the same conclusions, but presented in a different, in this case, more direct and conventional manner. This is an area where the subversive humorist can succeed in playfully revealing incongruities between one's consciously professed egalitarian beliefs and one's automatic biased language and action. 
the humor. ${ }^{22}$ Victor Raskin, who offers a seminal account of a semantic scripts theory of humor, notes that "humor is a very cooperative MC [mode of communication], and it is used for productive and efficient discourse when both sides, the speaker and the hearer(s), operate in the same mode" (Raskin 1992, 87). In subversive humor, this "same mode" is the playful attitude. This is not always the case going into a verbal engagement, but once the audience recognizes the play mode of the speaker this can both encourage them to get into play mode themselves, and thus openness, pulling them into a collaborative mission of fault-finding; a task that might otherwise be time-consuming and dull. In addition, without the playfulness and openness, the task would more likely be put off or completely derailed, especially if it involves an investigation into one's own potentially flawed beliefs.

This might at first appear counter-intuitive, especially as it is a common view of humor that it violates Grice's rules for proper communication, namely, his “Cooperative Principle” (CP) (Grice 1975). When one is following the non-conscious and unwritten (until Grice) rules of conversational logic, one avoids ambiguity, says only what one believes to be true, states only that for which one has evidence, is orderly, communicates as simply as possible, etc. Violation of these maxims, it is assumed, limits cooperation among conversants. Raskin and Attardo raise the important question, "How can such common examples of linguistic exchange in humor succeed in being understood at all?" One reason they offer is that humorous interaction is "ruled by a cooperative principle of its own which is just as stringent as the bona-fide communication cooperative principle." The non-bona-fide communication mode in humor is the "default non-bona-fide communication mode, or the one which is closest to bona-fide communication" (Raskin and Attardo 1994, 34-36). That is, we are more likely to interpret a seemingly non-cooperative expression as humor than we are to assume it is a case of lying or simple nonsense. Raskin and Attardo's neo-Gricean cooperative principle for humor lends support, in part, to my account of subversive humor as a serious effort to genuinely and collaboratively engage others in order to change attitudes.

The humorist is trying to create cognitive dissonance (or permit the mental spaces in which the audience can do so themselves), and flout the rules of con-

22 See Veale 2004, 422-23; Oring 2004, 18, and especially 55 on the "audience's playful participation"; and Duncombe 2007, 131: "Jokes are active, social things. More than any other form of communication they demand participation from their audience." Humor is therefore fundamentally different than many other art forms that might be enjoyable simply because of their structure, form, design, color, etc., with no comprehension or concern of content. Whether laughter can be aroused only if one espouses the content of the jokes is another matter. 
versation, logic, and society by relying upon a collaborative effort with the audience in which they must actively take part in the humor in a manner not found in direct communication, much less in argument. ${ }^{23}$ The more my presuppositions are made explicit, clearly defended, and rendered consonant with my premises, usually the better my argument will be. With humor, presuppositions are invoked, but often purposely hidden beneath some salient script(s) with which the wit intends to contrast in the end with a conclusion (punch line) that opposes, contradicts, or is different enough from the initial salient idea. This encourages the audience to reinterpret the entire presentation if they want any degree of resolution to the incongruity. But, since the default mode for interpreting apparent absurdity found in jokes or narrative hyperbole is to view it as humor, and we are driven by our attraction to the feelings of mirth, we are especially inclined to be more open and playfully assess the various possible meanings of the wit's language.

But denying that the joking or play-worlds created by humorists ever have any connection to truth in the 'real world', as "truth is irrelevant to joke-telling" (Raskin and Attardo 1994, 65), Raskin and Attardo, among others, ignore a large subset of humor, namely from subversive humorists, whose aim is to meaningfully connect a funny fictionalization with a serious reality. We should not be misled by the term "fiction"; the meaning and intentions in our playfully constructed scenarios can bleed into reality in such a way that listeners can be persuaded to see things from a fresh perspective, and possibly be convinced of the view espoused in the imaginative thought experiments of the subversive humorist. To claim, as Raskin and Attardo do, that all joke-worlds are unconcerned with truth, amounts to believing that all thought experiments have no connection to the real world, due to the violations of accepted rules and patterns in the logically possible realms.

The range of amusing incongruities and exceptions to general rules is quite broad, but some of those most related to the freedom of thought regarding norms, customs, and the social, intellectual, and ethical expectations include playing with points of view, categories, logical rules, linguistic rules, and the

23 There is an insightful and memorable Buddhist parable that might help make my point here, which I will paraphrase: Two monks who had taken vows of chastity, saw a woman in need of crossing a river. One monk silently (the monks were not allowed to speak until dinner) carried her across. Later, the other monk asked him, "Why did you touch that woman? We are not allowed such things." The first monk replied: "I set her down on the other side of the river hours ago. Why are you still carrying her?" If we read this from a purely logical standpoint, we might exclaim "Equivocation! Those are clearly two different senses of 'carrying." But of course, this would entirely miss the point. 
pragmatic rules of conversation, for example. Many of these overlap or are subsumed within each other, but each includes the development of novelty-seeking which is uncomfortable for the dogmatic serious person who seeks complacency in the familiar, or that which is congruous with his preconceptual background. When a playful attitude is fostered in aesthetically assembled thought experiments, we are more likely to allow our potentially inconsistent intuitions into consciousness so that we can amend them if necessary. Such a move is essential to engage in social change in the actual world.

\section{Subversive Humor and Imaginative Contagion}

One of the most interesting forms of subversive humor is the sort that is completely fabricated. That is, it is made up, invented, a creation from the mind of the wit or an act of fiction. Such acts of subversive humor are adult forms of playful pretending but can be about very serious matters, such as racism, sexism, homophobia, and oppression. In many cases in which counterfactuals are employed, a purely historical "what if” account is envisioned, as with Rahman's joke, but such hypothetical thinking can also project forward through imagining what would have to be the case for a desired state to be actualized. ${ }^{24}$

The "fictions" engaged in both subversive humor and thought experiments are not intended to remain solely internally consistent within the imaginative construction, having no practical implications for the real world corresponding to the joke-worlds. Rahman's performance is an instance of a thought experiment in which much of the content is not intended to be taken literally, and yet our intuitions are that he is motivated to convince us that (some of) his ideas are true. In Gendler's words, he wishes to "demonstrate" to his audience specific conclusions that are "novel justified true beliefs about the [social] world" (Gendler 1998, 411) even though he clearly does not intend for us to suspend our disbelief about the technological reality of time machines.

But a concern with any aesthetic work that makes things up, as with jokes and thought experiments, is "How can versions of nothing thus participate in the making of [or connection to] actual worlds?” (Goodman 1978, 103) as fictional

24 This kind of imaginative thought has commonly been practiced among athletes who, for example, "practice" shooting free throws in the "laboratory of their minds" resulting in comparable improvements to those who actually practice on the physical court. It is also invoked with subversive humorists as they imagine alternate realities in which they are no longer oppressed. For the humorous thought experiments of the marginalized, see Gilbert 2004, 178 and Duncombe Chapter 7 Dreampolitik; for the efficacy of imagination in protest, see Harvey 2010, 13-27. 
characters such as Don Quixote (his example) do not have any referents in the real world. This brings us to a question raised by Walton: "What relations can hold between the real world and fictional worlds?” (Walton 1978, 11) My argument assumes, expanding on Walton, that there is a permeable membrane between fictional joke-worlds and the real world: "The barrier between worlds is not airtight, however. There are epistemological holes in it. We know a great deal about what happens in fictional worlds... [and more to the point here] Along with our epistemological access to fictional occurrences goes a capacity to be affected by them. We respond to what we know about fictional worlds in many of the ways that we respond to what we know about the real world-or at least it seems that we do" (Walton 1978, 12). We do, and it is a feat of imagination that should not be underestimated.

Thought experiments as aesthetic worlds facilitate a reappraisal of our concepts not just by providing a jolt to our cognitive structures, but through stoking our emotions..$^{25}$ Gendler makes this point regarding the role of imagination, albeit in non-aesthetic cases, that when engaged in imaginative rehearsal of a certain practice, we can arrive at new beliefs that would otherwise be beyond our reach if we relied on reasoning in a disinterested manner. Her point, borrowing from Damasio's research on "somatic markers" which encode intelligent responses to emotionally salient data whether from one's immediate environment or a make-believe scenario, is that direct confrontation with an issue, assuming deductive or inductive inferences as the only means to reach a belief is often insufficient. This is the case with patients trying to overcome neuroses, or those afraid of public speaking or flying on an airplane. It is important to note that in many of these cases if asked whether they believed flying really is dangerous, e.g., the person in question would explicitly state they do not believe it is, as they are aware of the numerous statistics which reveal the greater likelihood of being stung and killed by a bee than dying in a plane crash. Nevertheless, the greater fear of flying remains. But this fear, which seems somewhat unresponsive to reasons in direct fashion, is responsive to mental imagery in fictionalized constructions. This is also the case with implicit biases that are less-thanreasons-responsive, that require "sub-rational mechanisms" to unearth and amend them.

25 Veale offers a similar view: "A strong emotive basis is also important in nurturing the desired response to a thought experiment, much as it is in humour, which often seeks a visceral reaction to a joke" (Veale 2015, 73), and "Thought experiments with a pronounced interpersonal dimension are more likely to engage the social instincts of a listener and achieve both an emotive and an intellectual effect” (Veale 2015, 82). 
How can imaginative experimentation in thought make actual differences in the real world? Here is Gendler: "The cognitive and behavioral manifestations associated with imaginative contagion are not marked as explicit episodes of pretense. Instead, they are actual responses to imagined content. Imaginative contagion occurs when source-indifferent features of our mental architecture process merely imagined input in the same way that nonimaginary input would have been processed, despite our recognition that the content in question is not reality reflective” (Gendler 2006, 188). So, we respond with real emotion and this-worldly ways even when we know the information before us is pretense in part or whole. This gives the author or humorous thought-experimenter much more freedom of imagination to stretch conventional thinking, instilling in audiences a "playful attitude" that allows us to "Notic[e] the tensions from within a logic of resistance [that] enables one to acquire a multiple sensing, a multiple perceiving, a multiple sociality" (Lugones 2003, 11). Without this, other social perspectives are ignored.

The realm of imagination is not confined to the real world of literal truth, or what we take the real world's literal truth to be, and this is a good thing if one of our aims is to change some aspect of the real world. But this requires a deft interweaving of fact and fiction where our minds are not confined to the "REAL/ HERE/NOW/ME/PRACTICAL" (Morreall 2009, 32), the "serious" realm of emotions, in Morreall's sense, for if they were, we would have very few chances of survival. Looking into the future, a time not yet, hence, in a non-trivial sense, a possible world of our imaginations, allows us to creatively and critically reflect on where we have been, what is the case here and now, and what we wish and even dream for (Duncombe 2007, 176-83) in a future state. This requires motivating emotions, ${ }^{26}$ contra Morreall, and not merely ratiocination.

A well-constructed thought experiment is in many ways akin to what Nelson Goodman calls "worldmaking." But "Worldmaking as we know it always starts from worlds already on hand; the making is a remaking” (Goodman 1978, 6). The possible worlds created by subversive humorists attempt a "reorganization of our familiar world" (Goodman 1978, 104), playing with thought, ideas, con-

26 Admittedly, there are cases in which there is an affective component to a humorous incongruity in which the degree of mirth might be increased due to feelings of animosity against the object of the humor. A separate article would be needed to adequately address this issue, but I would argue that if all that is involved are feelings of superiority over another, and no incongruity invoking laughter, then we are left with pure ridicule, not humor. This would be the case whether it comes from above or below, but due to the power differentials, it is always more harmful when it showers down from the "winner's circle." For more on the way an affective element might enhance amusement, see Roberts 2019, 103-08. 
cepts, words giving license to an audience to do the same as they collaboratively help to make meaning out of what might otherwise be considered non-bona-fide, ambiguous, made-up nonsense. The humorous wit can "take, and unmake and remake and retake familiar worlds and recast them in remarkable and sometimes recondite but eventually recognizable-that is, re-cognizable-ways" (Goodman 1978, 104-5). Subversive humor, like all humor, relies upon cognitive shifting and reframing of all sorts of rules, but instead of resenting, distressing, or feeling traumatized by the frame-shifting, we enjoy it so much that we even pay people to help facilitate such oscillations, and this can be the case even when the shifting entails a re-evaluation of our own cherished (and preidentified) rules, heuristics, and conventional categorizations: "We laugh not just because categories are subverted and their boundaries shown to be fuzzier than previously believed, but because there are social consequences of this subversion that we find psychologically satisfying" (Veale 2015, 88). These are real-world effects produced by thought experiments piquing our imaginations.

\section{Analysis of "Reverse Racism"}

Returning to the opening joke from Aamer Rahman, it is aesthetic in the above sense due to the creative, pleasurable experience, placing us in a play mode which invokes the appropriate emotions driving curiosity and openness to surprise. These allow us to maintain focus even as we might sit a bit uncomfortably through a reversal of actual white supremacist history, which acts as a not-sosubtle reminder of the reality. In play mode we are primed to be at the right distance, and can follow along with the creative constructions and even add input collaboratively when needed.

It is not easy to say something original, interesting, creative, imaginative, relevant, insightful, and amusing all at the same time, especially when the content concerns hotly contested matters of race and oppression. This bit hits all of those markers while exploding the historical and conceptual confusion inherent in the obfuscating phrase "reverse racism." Rahmer violates our expectations when he says "I can be a reverse racist," but once we recognize he has maneuvered us into a "what if" story, a counterfactual, we might be able to predict the conclusion. Nevertheless, we are compelled to tarry along with enjoyment until the punchline hits, and we can see what we likely had an inkling of all along ${ }^{27}$ be-

27 Recall Shelly's comment on poetry making the ordinary appear extraordinary. The comedian, like many philosophical thought-experimenters, “exaggerates or distorts his observations as a 
cause we possess the relevant intuitions-it is the case that anyone might be the victim of prejudice or discrimination; but his implied point, one we collaborate with in filling in, is that it is prejudice when coupled with historical power over all of the relevant systems of governance, law, education, employment, housing, military, health, etc., that sustains racism.

Logically, Rahman's piece loosely fits a form of reductio ad absurdum: suppose "reverse racism" were a real thing. What would have to be the case to make that so? Well, it would take a time machine and upending a central facet of Western history. The absurd conclusion is then something rather unwieldy when put in bona-fide non-humorous language: "reverse racism is possible when the marginalized person directs her jokes against a white hegemonic male, for instance, when that marginalized person belongs to a group that has power over all or most of the relevant systems of governance and social interaction." The contradiction hits us in the face with "subversive lucidity": the marginalized, oppressed, powerless person must be the dominant oppressor from the center. ${ }^{28}$ She cannot be both simultaneously.

This is an example of an aesthetically pleasing thought experiment that calls to our attention something that is likely obvious to many minorities who have to see and understand these issues as a matter of survival. ${ }^{29}$ Focused attention to racism submerged within common experiences is needed especially with the re-election of the one and only black President of the United States. This is because there is now an environment that, to the privileged at least, appears to be "post-racial" 30 and thus devoid of "real" racism among the majority, and claims

participant observer talking to people in his own society about the familiar cultural rules and behavior patterns in their and his own society. The audience may hear their own behavior described as if it is an alien culture in the sense that they knew that information all along but no one ever said it like that to them before. However, even though the comedian and his audience share culture, part of the cultural knowledge with which they operate is tacit (that is, hitherto unspoken)" (Koziski 1984, 61; my italics).

28 There are issues with intersectionality here, as power can be complex. Richard Pryor used subversive humor against a racist system, but at the same time, he had power vis- $a$-vis Chinese immigrants and women and he often denigrated both in his performances. See Watkins 1999, $558-60$.

29 "I think that most of us who are outside the mainstream of, for example, the United States dominant construction or organization of life are 'world' travelers as a matter of necessity and of survival" (Lugones 2003, 88). But survival in this sense relies upon a non-solipsistic world-view. Unlike the privileged, the marginalized do not have the luxury of assuming theirs is the only valid perspective on reality.

30 For instance, see Adam Serwer's piece in Mother Jones on the latest Supreme Court decision on key sections of the Voting Rights Act (2013). See also DiAngelo 2018. 
to the contrary constitute cynically "playing the race card," 31 or engaging in "reverse racism." There are even some who claim that the new oppressed class is the white, heterosexual, Christian, male. They are mistaken. ${ }^{32}$

\section{Conclusion}

One of the features of Rahmer's example that distinguishes it from a bad thought experiment is its “ability to direct the reader's attention to inadequacies in her conceptual scheme that she herself recognizes immediately, as soon as they are pointed out to her"(Gendler 1998, 413; my italics). It is true the comedian is directing our attention, but only in the fashion of offering helpful hints and openings to find the flaws for ourselves; he is not giving all of the relevant data (if even possible) all at once, doing all the work. The audience must become participants in the fault-finding process with the subversive humorist in a manner not found in direct logical argument, bona-fide unambiguous protest. ${ }^{33}$ The entire bit is less than three minutes, even though he successfully navigates a counter-historical narrative, a "what if" story, that is a reversal of the actual history of white supremacy. His economy of language leaves openings for his audience to fill in collaboratively the details necessary to achieve his punchline (con-

31 Somewhat incongruously, there is also the claim made by the same people in this post-racial society that President Obama has only been re-elected because he is black! See The Colbert Report 2012. See also Monahan 2011, 5, referencing the comments of the same George Will that the election of a black president has rendered race irrelevant. The inconsistency of Will's claims is glaring, especially when humorously re-presented by Stephen Colbert. See also Duncombe 2007, 161, quoting the Onion: “'on the occasion of Rosa Parks's death, as her body lay in wait in the Capitol Rotunda and President Bush placed a wreath upon her casket, "Now We Can Finally Put Civil Rights Behind Us.”

32 See Cassino 2016. One can be wrong about where one lies on the socio-political spectrum and about how much power one actually possesses. The facts matter. See Munin 2012 for the recent statistics on the wide disparities in access for black children on all relevant dimensions from housing, healthcare, education, healthy food, healthy air and water, to unequal treatment in the justice system. The very point of Rahman's reverse racism bit is that racism and oppression require systematic power that, for example, white, heterosexual, Christian, males still possess in virtually ALL of the sectors mentioned above.

33 "Humor is just one way that politicos have figured out how to create a spectacle that engages people, making them into active participants ("livers") even in the very spectacles they enjoy just watching” (Duncombe 2007, 132-33). 
clusion). He gets us to visualize a situation in order to carry out an operation and see what happens in our minds, from which we draw a conclusion. ${ }^{34}$

This collaboration places much of the task of meaning and understanding on the audience, which means that they "own" the attitude change, to the extent that it occurs, or that they are co-authors of it, which can help alleviate the anxiety and discomfort due to a shift in perspectives. When one is playful one can discern the intentions of a speaker in ways not available in the default serious mode; meanings are not absolute and fixed, but contingent, as are the hierarchical and oppressive structures resisted by the subversive humorist.

Covert "civilized" oppression (Harvey 1999) causes psychological harms and results in legal and economic exclusion every bit as real as overt, but caused by concealed and systemic mechanisms such as implicit biases and stereotypes. Since many of these biases are not consciously reasoned into one's system of beliefs, and since they are notoriously difficult to bring to consciousness and dislodge via direct, logical confrontation, some other creative means of resistance should be considered. A less conventional and more imaginative approach is needed, but one that does not rely upon traditional rule-following, one-dimensional thinking, nor one that attacks the status quo merely to delight in a pure aesthetic experience. Subversive humor employs aesthetics and logic, playfulness and seriousness, emotion and reason. To the extent that it works for oppressed people toward establishing psychological distance, encouraging disinterested third-party bystanders (to the extent that there are such beings) to recognize their struggle, and possibly even get the oppressors to recognize them as equal human beings, subversive humor is significantly efficacious toward combating oppression. ${ }^{35}$

\section{References}

Basu, Sammy. 1999. "Dialogic Ethics and the Virtue of Humor." The Journal of Political Philosophy 7(4): 378-403.

34 A helpful image related to embodiment in thought experiment can be found with the tactics invented by "memory champions" who use visual imagery called a "memory palace" first used by the poet Simonides (see Foer 2011). It is not insignificant that the more outlandish and amusing the imagery one connects to otherwise quotidian objects, as one mentally walks through their memory palace built in their imagination, the easier it is to recall them.

35 Much of the research for this article originates from my dissertation, Subversive Humor (Marquette, 2015). I am thankful for the anonymous reviewers and their helpful comments and suggestions, and especially thankful for all of the fun and fruitful conversations with the fine folks of the Lighthearted Philosophers' Society. 
Buckley, Frank H. 2005. The Morality of Laughter: A Serious Look at the Meaning of Laughter. Ann Arbor: University of Michigan Press.

Carroll, Noël. 2000. "Ethnicity, Race, and Monstrosity: The Rhetorics of Horror and Humor." In Beauty Matters, edited by Peg Zeglin Brand, 37-56. Bloomington: Indiana University Press.

Carroll, Noël. 2003. "Humor." In The Oxford Handbook of Aesthetics, edited by Jerrold Levinson, 344-65. Oxford: Oxford University Press.

Cassino, Dan. 2016. "Why More American Men Feel Discriminated Against." New York Times, September 29, 2016. Accessed October 25, 2019. https://hbr.org/2016/09/why-moreamerican-men-feel-discriminated-against.

The Colbert Report. 2012. "Washington Post columnist and African-American pioneer George Will believes that President Obama is only leading in the polls because he is black." Accessed February 3, 2013. http://www.colbertnation.com/the-colbert-report-videos/ 419766/october-03-2012/george-will-s-political-post-racial-journalism.

Damasio, Antonio. 1994. Descartes' Error: Emotion, Reason, and the Human Brain, New York: Grosset/Putnam.

Dennett, Daniel. 2013. Intuition Pumps and other Tools for Thinking. New York: Norton.

Diamond, Stanley. 1982. "Subversive Art." Social Research 49(4): 854-77.

DiAngelo, Robin. 2018. White Fragility: Why It's So Hard for White People to Talk About Racism. Boston: Beacon Press.

Duncombe, Stephen. 2007. Dream: Re-imagining Progressive Politics in an Age of Fantasy. New York: The New Press.

Elder, Linda. 1996. “Critical Thinking and Emotional Intelligence.” Inquiry: Critical Thinking Across the Disciplines 16(2): 35-46.

Foer, Joshua. 2011. Moonwalking with Einstein: The Art and Science of Remembering Everything. New York: The Penguin Press.

Freud, Sigmund. 1960. Jokes and Their Relation to the Unconscious. New York: Norton.

Geertsema, Johan. 2004. "Ndebele, Fanon, Agency and Irony." Journal of Southern African Studies 30(4): 749-63.

Gendler, Tamar. 1998. "Galileo and the Indispensability of Scientific Thought Experiment." The British Journal for the Philosophy of Science 39(3): 397-424.

Gendler, Tamar. 2006. “Imaginative Contagion.” Metaphilosophy 37(2): 183-203.

Gendler, Tamar. 2007. "Philosophical Thought Experiments, Intuitions, and Cognitive Equilibrium." Midwest Studies in Philosophy 31: 68-89.

Gendler, Tamar, and Karson Kovakovich. 2006. "Genuine Rational Fictional Emotions." In Contemporary Debates in Aesthetics and the Philosophy of Art, edited by Matthew Kieran, 241-53. Malden: Blackwell.

Gilbert, Joanne R. 2004. Performing Marginality: Humor, Gender, and Cultural Critique. Detroit: Wayne State University Press.

Gooding, David. 1998. “Thought Experiments.” In Routledge Encyclopedia of Philosophy, vol. 9, edited by Edward Craig, 392-97. London: Routledge.

Goodman, Nelson. 1978. Ways of Worldmaking. Indianapolis: Hackett.

Gordon, Mordechai. 2012. "What Makes Humor Aesthetic?" International Journal of Humanities and Social Science 2(1): 62-70.

Grice. Herbert P. 1975. "Logic and Conversation." In Syntax and Semantics 3: Speech Arts, edited by Peter Cole and Jerry L. Morgan, 41-58. London: Elsevier. 
Harvey, Jean. 1999. Civilized Oppression. Lanham: Rowman and Littlefield.

Harvey, Jean. 2010. "Victims, Resistance, and Civilized Oppression," Journal of Social Philosophy 41(1): $13-27$.

Hurley, Matthew, Daniel Dennett, and Reginald Adams Jr. 2011. Inside Jokes: Using Humor to Reverse-Engineer the Mind. Cambridge: MIT Press.

Jones, Ward E. 2006. "The Function and Content of Amusement." South African Journal of Philosophy 25(2): $126-37$.

Koestler, Arthur. 1964. The Act of Creation: A Study of the Conscious and Nonconscious Processes in Humor, Scientific Discovery and Art. New York: The Macmillan Company.

Koziski, Stephanie. 1984. "The Standup Comedian as Anthropologist: Intentional Culture Critic." Journal of Popular Culture 18(2): 57-76.

Lakoff, George, and Mark Johnson. 1980. Metaphors We Live By. Chicago: University of Chicago Press.

Lear, Jonathan. 2009. "To Become Human Does Not Come That Easily." The Tanner Lectures on Human Values Harvard University 4-6: 261-301.

Lugones, Maria. 2003. Pilgrimages/Peregrinajes: Theorizing Coalition against Multiple Oppressions. Lanham: Rowman and Littlefield.

Mach, Ernst. 1972. On Thought Experiments. Translated by W. O. Price and Sheldon Krimsky. Accessed May 11, 2014. www.tufts.edu/.../On\%20Thought\%20Experiments.PDF.

Marmysz, John. 2003. Laughing at Nothing: Humor as a Response to Nihilism. Albany: State University of New York Press.

Martin, Rod A., and Thomas E. Ford 2018. The Psychology of Humor: An Integrative Approach. $2^{\text {nd }}$ edition. London: Elsevier.

Medina, Jose. 2013. The Epistemology of Resistance: Gender and Racial Oppression, Epistemic Injustice, and Resistant Imaginations. Oxford: Oxford University Press.

Minsky, Marvin. 1984. "Jokes and the Logic of the Cognitive Unconscious." In Cognitive Constraints on Communication, edited by Vaina and Hintikka Reidel, 175-200. Dordrecht: Springer.

Monahan, Michael. 2011.The Creolizing Subject: Race, Reason, and the Politics of Purity. New York: Fordham University Press.

Morreall, John. 1983. Taking Laughter Seriously. Albany: State University of New York Press.

Morreall, John. 1987a. "Funny Ha-Ha, Funny Strange, and Other Reactions to Incongruity." In The Philosophy of Laughter and Humor, edited by John Morreall, 212-24. Albany: State University of New York Press.

Morreall, John. 1987b. "Humor and Emotion." In The Philosophy of Laughter and Humor, edited by John Morreall, 188-207. Albany: State University of New York Press.

Morreall, John. 1999. Comedy, Tragedy, and Religion. Albany: State University of New York Press.

Morreall, John. 2009. Comic Relief: A Comprehensive Philosophy of Humor. Malden: Wiley and Sons.

Munin, Art. 2012. Color by Number: Understanding Racism Through Facts and Stats on Children. Sterling: Stylus Publishing.

Oring, Elliot. 2003. Engaging Humor. Urbana and Chicago: University of Illinois Press.

Rahman, Aamer. 2013. "Aamer Rahman (Fear of a Brown Planet)-Reverse Racism.” YouTube video, 2:48. November 28, 2013. Accessed September 2, 2016. https://www.youtube. com/watch?v=dw_mRalHb-M. 
Raskin, Victor. 1979. "Semantic Mechanisms of Humor." Proceedings of the Fifth Annual Meeting of the Berkeley Linguistics Society. Published online by The Annual Proceedings of the Berkeley Linguistics Society: 325-35. Accessed June 10, 2013.

Raskin, Victor. 1992. "Humor as a Non-Bona-Fide Mode of Communication." DLLS Proceedings: 87-92.

Raskin, Victor, and Salvatore Attardo. 1994. "Non-literalness and Non-bona-fide in Language: An Approach to Formal and Computational Treatments of Humor." In Pragmatics and Cognition 2(1): 31-69.

Roberts, Alan. 2019. A Philosophy of Humour. London: Palgrave Macmillan.

Rooney, Phyllis. 2010. "Philosophy, Adversarial Argumentation, and Embattled Reason." Informal Logic 30(3): 203-34.

Rorty, Richard. 1993. Contingency, Irony, and Solidarity. New York: Cambridge University Press.

Sánchez, Carlos Alberto. 2012. The Suspension of Seriousness: On the Phenomenology of Jorge Portilla. Albany: State University of New York Press.

Schopenhauer, Arthur. 1887. The World as Will and Idea: Volume II. Translated by R. B. Haldane and J. Kemp. Boston: Ticknor and Company.

Serwer, Adam. 2013. "Supreme Court Poised to Declare Racism Over." Mother Jones, February 27, 2013. Accessed June 25, 2013.

http://www.motherjones.com/politics/2013/02/supreme-court-poised-declare-racism-over.

Veale, Tony. 2004. “Incongruity in Humor: Root Cause or Epiphenomenon?" Humor: International Journal of Humor Research 17(4): 419-28.

Veale, Tony. 2015. "The Humour of Exceptional Cases: Jokes as Compressed Thought Experiments." In Cognitive Linguistics and Humour Research, edited by Geert Brône, Kurt Feyearts, and Tony Veale, 69-90. Berlin: De Gruyter.

Walton, Kendall. 1978. "How Remote are Fictional Worlds from the Real World?" The Journal of Aesthetics and Art Criticism 37(1): 11-23.

Walton, Kendall, and Michael Tanner 1994. "Morals in Fiction and Fictional Morality." Proceedings of the Aristotelian Society, Supplementary Volumes 68: 27-66.

Watkins, Mel. 1999. On the Real Side: A History of African American Comedy from Slavery to Chris Rock. Chicago: Lawrence Hill Books.

Weisfeld, Glenn E. 2006. "Humor Appreciation as an Adaptive Esthetic Emotion.” Humor: International Journal of Humor Research 19(1): 1-26.

Yancy, George. 2008. "Elevators, Social Spaces, and Racism: A Philosophical Analysis." Philosophy and Social Criticism 34(8): 843-76.

Ziv, Avner. 1983. "The Influence of Humorous Atmosphere on Divergent Thinking." Contemporary Educational Psychology 8: 68-75.

Ziv, Avner. 1988. "Teaching and Learning with Humor: Experiment and Replication." Journal of Experimental Education 57(1): 5-15. 